\title{
Qualificação Docente: capacitação para utilização do Google Classroom em meio à pandemia de COVID-19
}

\author{
Sidnei Renato Silveira, Adriana Camargo Saldanha Machado, Cristiano Bertolini, \\ Maurício Bones Figueiró, Nara Martini Bigolin, Rodrigo Gobbi, Sandro Oliveira \\ da Silva \\ Curso de Licenciatura em Computação - Universidade Aberta do Brasil \\ (UAB)/Universidade Federal de Santa Maria (UFSM) - Campus Frederico \\ Westphalen/RS \\ Caixa Postal 54 - 94800-000 - Frederico Westphalen - RS \\ sidnei.silveira@ufsm.br, adrysaldanha@yahoo.com.br, cristia- \\ no.bertolinidufsm.br, mauricio_figueirodlive.com, gobbidcertto.net, \\ sanolisilva@hotmail.com
}

\begin{abstract}
Resumo: Este artigo apresenta os resultados de uma qualificação docente, na modalidade de EaD - Educação a Distância, visando a preparar os professores de escolas públicas para utilizarem a plataforma Google Classroom em suas atividades pedagógicas, tendo-se em vista o isolamento social adotado em meio à pandemia de COVID-19. Como as atividades letivas estão sendo realizadas por meio do ensino remoto, algumas instituições de ensino estão empregando TDICs (Tecnologias Digitais da Informação e da Comunicação), tais como a ferramenta Google Classroom. Os resultados preliminares do projeto mostram que os participantes da qualificação estão satisfeitos com a sua aprendizagem e com as possibilidades de empregar o Google Classroom em suas atividades docentes.
\end{abstract}

Palavras-chave: Qualificação Docente, Google Classroom, Pandemia de COVID-19.

\begin{abstract}
This paper presents the results of teacher qualification, in the modality of Distance Education, aiming to prepare public school teachers to use the Google Classroom platform in their pedagogical activities, because of the social isolation adopted during COVID-19 pandemic. As teaching activities are using remote teaching, some educational institutions are employing TDICs (Digital Information and Communication Technologies), such as the Google Classroom tool. The preliminary results of the project show that the qualification participants are satisfied with their learning and with the possibilities of using Google Classroom in their teaching activities.
\end{abstract}

Keywords: Teacher Qualification, Google Classroom, COVID-19 Pandemic

\section{Introdução}

Neste ano de 2020 professores e alunos estão vivenciando uma situação totalmente nova frente à pandemia de COVID-19. Devido ao isolamento social, para evitar o contágio do 
coronavírus, as instituições de ensino estão fechadas e todas as atividades ligadas aos processos de ensino e de aprendizagem estão sendo desenvolvidas a distância. Algumas escolas estão solicitando que os pais dos alunos busquem, semanalmente, atividades que são entregues de forma impressa. Outras estão utilizando recursos das TDICs (Tecnologias Digitais da Informação e da Comunicação), tais como e-mail, WhatsApp e AVAs (Ambientes Virtuais de Aprendizagem) (Costa, 2020; Sponchiato, 2020).

A SEDUC (Secretaria de Educação do Estado do Rio Grande do Sul) definiu que, a partir de junho, as atividades letivas nas Escolas Públicas Estaduais seriam desenvolvidas de forma remota, por meio do Google Classroom (Seduc-RS, 2020). Sendo assim, alunos e professores do Curso de Licenciatura em Computação, ofertado na modalidade de EaD (Educação a Distância) pela UAB/UFSM (Universidade Aberta do Brasil/Universidade Federal de Santa Maria) decidiram desenvolver um projeto de extensão, visando à qualificação dos docentes das escolas públicas estaduais. O projeto compreende a realização de cursos de extensão, ministrados por acadêmicos do referido curso, sob a supervisão de docentes, servindo como mais uma ferramenta de apoio aos professores (além das capacitações já oferecidas pela SEDUC-RS), para que os mesmos sejam capacitados e tenham um canal para esclarecer dúvidas e trocar experiências com outros docentes.

Alguns acadêmicos do Curso de Licenciatura em Computação já atuam como docentes em Escolas Públicas Estaduais do RS, já que possuem graduações anteriores em outras áreas. Sendo assim, ao perceberem as dificuldades e os anseios de seus colegas docentes decidiram, em parceria com alguns professores do curso, desenvolver uma qualificação que permitisse um contato mais próximo (mesmo que na modalidade de $\mathrm{EaD}$ ), visando a auxiliar os colegas professores, bem como estabelecer um canal de comunicação permanente, para apoiar o desenvolvimento das atividades pedagógicas na modalidade de ensino remoto.

O Google Classroom (ou Google Sala de Aula) é uma ferramenta gratuita para escola, organizações sem fins lucrativos e qualquer usuário que tenha uma conta do Google pessoal. A ferramenta permite a criação de turmas, distribuição de tarefas, comunicação entre os participantes e organização do espaço da sala de aula virtual. A ferramenta permite a inserção de tarefas e atribuição de notas às mesmas. A interação entre os professores e alunos pode ser realizada por meio do mural da turma. Além disso, a ferramenta permite a inserção de vídeos, um dos recursos mais utilizados atualmente pelos professores, em meio ao isolamento social (Google, 2020).

Neste contexto, o presente artigo apresenta os resultados de um projeto de extensão desenvolvido para auxiliar os docentes a utilizarem recursos de TDICs em seu fazer pedagógico, por meio da ferramenta Google Classroom. O projeto objetivou qualificar docentes que atuam na Educação Básica, de Escolas Públicas Estaduais do RS, interessados em desenvolver suas atividades pedagógicas por meio da ferramenta Google Classroom. Para tanto, utilizou-se a modalidade de EaD. O projeto foi desenvolvido de forma gratuita.

O artigo está estruturado como segue. A seção 2 apresenta uma breve fundamentação teórica, destacando as questões que envolvem o ensino remoto, ministrado de forma emergencial, durante a pandemia de COVID-19. A seção 3 apresenta alguns trabalhos relacionados, compreendendo a qualificação de docentes para o uso do Google Classroom. A seção 4 apresenta a metodologia empregada para o 
desenvolvimento dos cursos de extensão, em nível de qualificação. A seção 5 apresenta os resultados alcançados até o momento. Encerrando o artigo são apresentadas as considerações finais e as referências empregadas.

\section{Fundamentação Teórica}

Neste ano de 2020 professores e alunos estão vivenciando uma situação totalmente nova em decorrência da pandemia de COVID-19. Devido ao isolamento social, para evitar o contágio do coronavírus, as instituições de ensino estão fechadas e todas as atividades ligadas aos processos de ensino e de aprendizagem estão sendo desenvolvidos de forma remota (Costa, 2020; Sponchiato, 2020). O que se verificou, por meio da observação do trabalho desenvolvido pelos docentes, é que a maioria não estava preparada para desenvolver as atividades mediadas pelas TDICs (Instituto Península, 2020) e, além disso, não estava preparada para definir e adotar uma metodologia que não usasse um AVA (Ambiente Virtual de Aprendizagem) apenas como um repositório de textos e de entrega de atividades, repetindo o modelo tradicional de ensino, apenas alterando-o para o meio digital. Tal observação revela que existe uma lacuna na formação docente, no que envolvem não só as TDICs mas, também, o uso de metodologias de ensino adequadas.

Como estamos em meio ao isolamento social devido à pandemia de COVID-19, os encontros presenciais estão suspensos. Sendo assim, os encontros entre os professores e alunos têm sido realizados de forma virtual, por meio da aplicação das TDICs, em especial as ferramentas de comunicação por meio da Internet.

Neste sentido, faz-se necessário que os docentes participem de ações de qualificação para que eles possam utilizar estas ferramentas da maneira adequada, incentivando a interação tanto do professor com os seus alunos como entre os próprios alunos, visando o aproveitamento do que há de melhor em cada uma dessas ferramentas de forma a permitir um compartilhamento efetivo de conhecimento. Segundo Pimentel e Carvalho (2020), este é um momento oportuno para discutir a prática pedagógica, pois a pandemia do COVID-19 é uma situação sem precedentes.

Além de utilizar as TDICs, para apoiar os processos de ensino e aprendizagem em meio à pandemia da COVID-19, essas tecnologias podem ser utilizadas para ofertar, para os próprios docentes, programas de formação continuada, ou seja, além dos docentes ensinarem por meio das TDICs, eles também podem aprender por meio delas, como é o caso do projeto de extensão apresentado neste artigo. A utilização das TDICs é um ponto importante para a inclusão digital, tão necessária na atual sociedade do conhecimento.

Entretanto, a urgência na realização das atividades a distância deixou clara a desigualdade que existe entre os públicos das instituições públicas e privadas, bem como a dificuldade dos docentes para aplicarem as TDICs em suas atividades. Segundo resultados de uma pesquisa realizada pelo Instituto Península, $83 \%$ dos docentes não se sentem preparados para desenvolver suas atividades a distância e, grande parte, faz o contato com pais e alunos apenas via whatsapp. Esta mesma pesquisa ainda revela que 90\% dos professores nunca tinham atuado na modalidade a distância e 55\% não receberam nenhum tipo de apoio ou treinamento para desenvolverem essas atividades (Instituto Península, 2020). As questões socioeconômicas também estão presentes, 
distanciando os professores e alunos de escolas privadas (que possuem recursos para dar o suporte tecnológico necessário para a realização das atividades a distância) e os pertencentes às escolas públicas, com maiores dificuldades, inclusive de acesso à Internet (Coradini, 2020; Tenente, 2020).

Recentemente a SEDUC-RS divulgou informações sobre a retomada das aulas, de forma remota, nas Escolas Públicas Estaduais, adotando como ferramenta o Google Classroom (Seduc-RS, 2020). Neste contexto é que se justifica a realização desta qualificação docente e, também, a escolha da ferramenta Google Classroom.

\section{Trabalhos Relacionados}

Toledo, Rocha e Nunes (2018) desenvolveram um projeto de qualificação de docentes de uma universidade do Estado de Sergipe - Universidade Tiradentes, para o uso do Google Classrom. A qualificação faz parte de um projeto com um escopo maior, denominado Tiradentes Digital. O Google Classroom foi escolhido por proporcionar dinamicidade ao ambiente educacional, além de ser um ambiente já empregado por docentes e discentes da referida instituição. A qualificação foi realizada, inicialmente, com 39 docentes, que participaram de um treinamento visando à formação de Embaixadores Google, para que os mesmos atuassem como disseminadores desta tecnologia na instituição. Diferentemente da proposta apresentada neste artigo, o foco do trabalho não é a Educação Superior e, sim, a Educação Básica, especificamente voltada aos professores de Escolas Públicas Estaduais do RS.

Mehlecke et al (2019) desenvolveram uma proposta de qualificação docente, voltada aos docentes da Educação Superior de uma instituição localizada no município de Taquara - RS, compreendendo a aplicação do Google Classroom e da metodologia ativa de aprendizagem denominada Sala de Aula Invertida. O Google Classrom, de acordo com esta metodologia, foi utilizado para apresentar aos docentes participantes da qualificação, materiais didáticos que deviam ser estudados antes dos momentos de interação com os demais participantes, a chamada pré-aula. A qualificação docente faz parte de um projeto denominado Compartilha + , tendo sido desenvolvida no ano de 2017. Assim como o trabalho anterior, este também é voltado para a Educação Superior, diferentemente do trabalho desenvolvido.

Além dos trabalhos apresentados, outras instituições de ensino já realizaram qualificações docentes e incorporaram o Google Classroom no fazer pedagógico. Entretanto, antes da pandemia de COVID-19, não foram encontrados trabalhos sobre a aplicação na modalidade de ensino remoto, mais especificamente voltados a professores de Escolas Públicas, já que essa modalidade é emergencial e não havia sido aplicada anteriormente.

\section{Planejamento da Qualificação Docente}

O planejamento da qualificação docente, por meio de um projeto de extensão, foi desenvolvido pensando-se em uma metodologia de ensino que estimulasse a participação, dentro de um processo de interação entre os docentes e discentes, tendo como público-alvo os professores da Educação Básica do Estado do Rio Grande do Sul, integrantes da $20^{\mathrm{a}} \mathrm{CRE}$ (Coordenadoria Regional de Educação). 
Para a divulgação deste projeto, realizou-se uma breve pesquisa entre os professores, por meio da utilização da ferramenta WhatsApp (com o apoio da 20 a CRE), visando identificar o interesse dos mesmos em participar. Após analisar a necessidade de aperfeiçoamento e qualificação do público-alvo, bem como suas dúvidas em relação ao uso das TDICs, optou-se por utilizar como ferramenta para esta capacitação docente a Plataforma Google Classroom, o que se justifica devido ao momento de distanciamento social e por ser a ferramenta adotada pelo Governo do Estado do RS.

Para divulgar este projeto de extensão, utilizou-se um texto informativo com os principais dados do projeto, uma breve explanação de seus componentes, contendo também um tutorial de acesso à sala de aula virtual. Seguindo o tutorial, o professor interessado ingressa na sala de aula on-line por meio do código de cada turma ofertada. Foi criado, também, um cartaz informativo com dados do projeto, data de início de cada turma e um número de telefone para eventuais sanar dúvidas aos interessados em participar da qualificação. A qualificação foi baseada em vídeoaulas, apresentações de slides e documentos, entre outros materiais didáticos-digitais.

O planejamento de cada turma do curso prevê o desenvolvimento de quatro atividades práticas, que são avaliadas pelos colaboradores do presente projeto. Todo aluno que tiver aproveitamento mínimo de $75 \%$ será aprovado e terá direito ao certificado de conclusão.

As atividades são divididas em etapas, proporcionando assim, uma melhor compreensão da ferramenta utilizada. Sendo assim, o planejamento previu o desenvolvimento de treze aulas, assim distribuídas:

Aula 1 - Vídeoaula (abertura da turma);

Aula 2 - Introdução ao Google Classroom;

Aula 3 -Gerando o e-mail @educar;

Aula 4 - Como ingressar na sala de aula on-line com o e-mail institucional;

Aula 5 - Criação e correção de atividades no Google Classroom;

Aula 6 - Reaproveitamento de postagens no Google Classroom;

Aula 7 - Como postar a mesma atividade para várias turmas;

Aula 8 - Organizando aulas e atividades em Tópicos no Google Classroom;

Aula 9 - Dicas de como usar o Google Classroom com seus alunos;

Aula 10 - Utilizando o Google Drive com o Google Classrooom;

Aula 11 - Criando documentos compartilhados com os alunos usando o Google Docs;

Aula 12 - Criando formulários no Google Classroom;

Aula 13 - Encerramento do Curso de Google Classroom.

Os discentes e docentes responsáveis pelo projeto, durante cada uma das edições da qualificação, realizarão o acompanhamento pedagógico das atividades desenvolvidas, bem como, responderão e auxiliarão aos participantes sempre que 
necessário, garantindo que haja interação e participação efetiva, monitorando e avaliando as atividades realizadas periodicamente.

Ficou estabelecido que cada turma ofertada para a qualificação teria cem alunos, cujas inscrições ocorrerão por ordem de chegada, estabelecendo-se como público-alvo os professores pertencentes à $20^{\mathrm{a}} \mathrm{CRE}-\mathrm{RS}$.

\section{Resultados Obtidos}

Estão sendo realizadas, nesta $1^{a}$ fase do projeto, duas edições da referida qualificação docente. Em cada uma das edições foram ofertadas 100 (cem) vagas, destinadas a docentes que atuam na Educação Básica. A inscrição foi realizada por meio do link classroom.google.com onde os professores devem informar o código da turma e clicar em Participar, ingressando na sala de aula on-line.

A primeira turma do curso iniciou as atividades na metade do mês de junho deste ano. Atualmente a segunda turma já se encontra em atividade. Dos cem inscritos inicialmente na primeira turma, trinta e cinco participantes (representando 35\%) concluíram as atividades satisfatoriamente (considerando o aproveitamento estipulado de $75 \%$ ) e preencheram o formulário contendo a avaliação do curso. A avaliação foi realizada a fim de verificar se os participantes compreenderam como aplicar a ferramenta Google Classroom em sua prática pedagógica, além de identificar possíveis melhorias e conteúdos que poderiam ser abordados em novas qualificações.

O formulário de avaliação foi construído com a ferramenta Google Forms, utilizando-se uma escala do tipo Likert com cinco pontos (Silva Júnior; Costa, 2014), contendo as seguintes opções de resposta para as perguntas fechadas: Muito Bom, Bom, Indiferente, Regular e Insatisfatório.

A primeira pergunta do formulário de avaliação era " $O$ curso atendeu as suas expectativas?". Dos trinta e cinco respondentes, $91,4 \%$ destacou o conceito Muito Bom e $8,6 \%$ respondeu Bom.

Como segundo questionamento, teve-se: "Aplicabilidade da ferramenta Google Classroom no seu trabalho". Para esta questão, 94,3\% dos respondentes destacou a opção Muito Bom e 5,7\% Bom.

De acordo com o instrumento de pesquisa, a terceira pergunta compreendia " $A$ organização do curso favoreceu o seu processo de aprendizagem?". 85,7\% dos respondentes destacou Muito Bom, 11,4\% Bom e 2,9\% Regular.

A quarta questão envolveu os materiais didáticos-digitais disponibilizados no curso, perguntando-se se os mesmos foram suficientes para que os participantes compreendessem os conteúdos propostos. 85,7\% destacaram Muito Bom e 14,3\% Bom.

Perguntou-se, também, a impressão dos participantes sobre o seu nível de conhecimento antes de participarem do curso. 37,1\% destacaram que o conhecimento prévio era Insatisfatório, 34,3\% Regular, 25,7\% Bom e 2,9\% Muito Bom. Visando identificar o nível de conhecimento após a conclusão do curso, repetiu-se a pergunta, após a conclusão do mesmo. 48,6\% dos participantes considera que o nível de conhecimento passou a ser Muito Bom, o mesmo percentual de 48,6\% considera Bom e 2,9\% considerou Indiferente. Estes resultados mostram que os participantes acreditam 
que desenvolveram seus conhecimentos com o curso, já que o percentual de conhecimento Muito Bom saltou de 2,9\% para 48,6\%.

A Figura 1 apresenta, de forma gráfica, os resultados das questões fechadas.

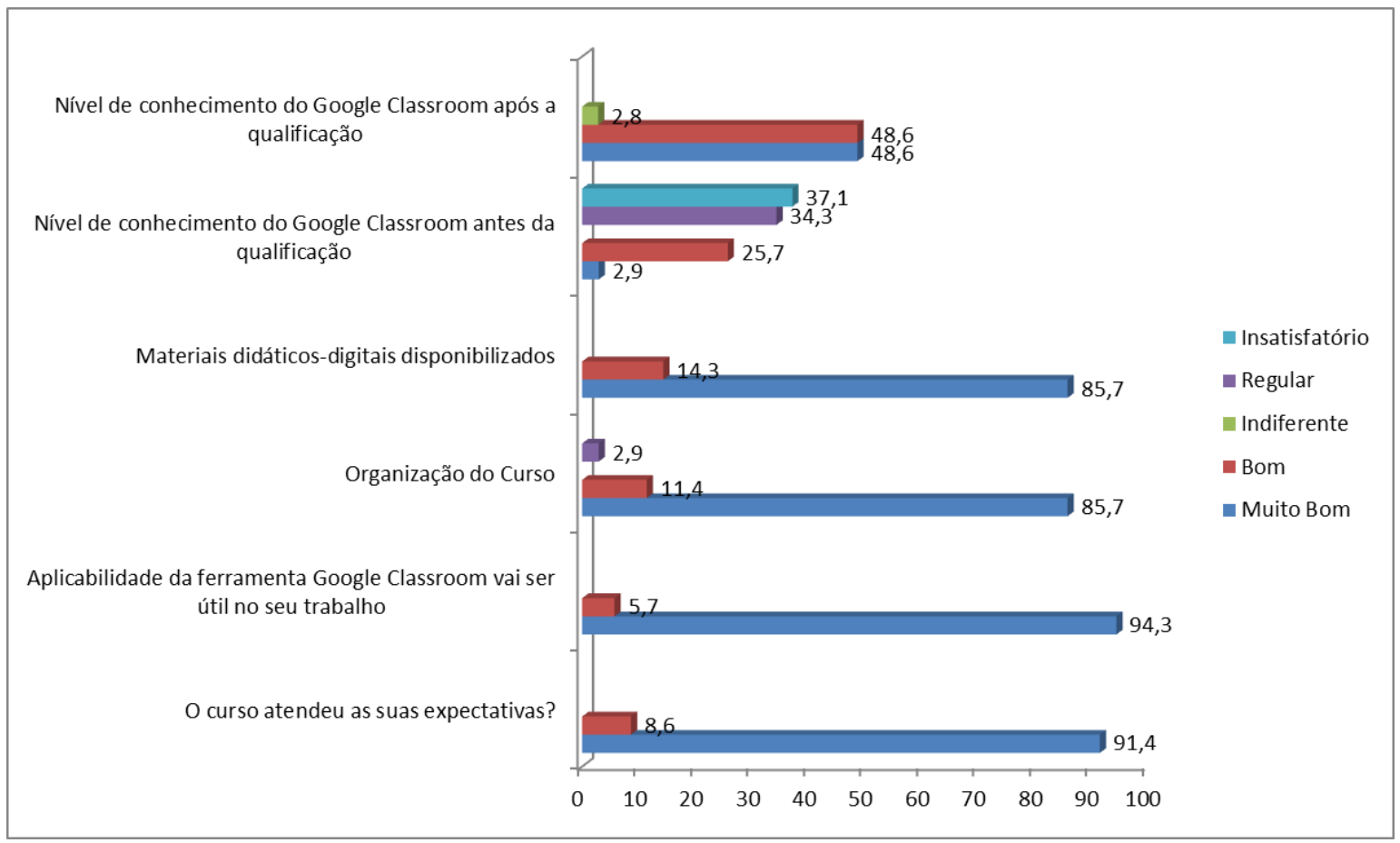

Figura 1 - Resultados das Questões Fechadas Fonte: Os autores, 2020

Além das perguntas fechadas, o instrumento continha três questões abertas. A primeira e segunda, solicitando que os participantes destacassem, respectivamente, potencialidades e limitações do curso e uma terceira pergunta, abrindo espaço para sugestões.

O Quadro 1 apresenta as principais potencialidades, categorizadas, destacadas pelos participantes. A categorização foi realizada tomando-se por base a análise de conteúdo, proposta por Bardin (2010), a partir das respostas abertas dos participantes. Ao lado da categoria, entre parênteses, apresenta-se a frequência em que a mesma apareceu nas respostas.

Quadro 1 - Principais Potencialidades da Qualificação

\begin{tabular}{|c|}
\hline Materiais Didáticos (12) \\
\hline Atividades Práticas (8) \\
\hline Metodologia de Ensino Empregada (7) \\
\hline Organização das Atividades (7) \\
\hline Disponibilidade dos Professores para o esclarecimento de dúvidas (5) \\
\hline
\end{tabular}

Fonte: Os autores, 2020

Destacando-se algumas opiniões dos participantes, na íntegra, tem-se: "As práticas. É preciso fazer para aprender"; “A facilidade de compreensão dos vídeos explicativos"; "Com o decorrer do curso percebi que é possível dar uma aula dinâmica a 
partir das ferramentas da plataforma"; "O curso começou com conhecimentos prévios e foi mostrando as ferramentas de diferentes formas através dos vídeos. Será muito bom poder acessar os vídeos, porque pode aparecer uma dúvida que poderemos acessar e entender. Para o aprendizado é tudo mais positivo"; "Gostei da forma com que conduziram as atividades, foi bem criativo e lúdico, sendo assim facilitando a aprendizagem".

O Quadro 2 apresenta as principais limitações, categorizadas, destacadas pelos participantes. A maioria dos respondentes não destacou nenhuma limitação (17 respondentes - 48,57\%). A principal limitação destacada foi a falta de tempo dos participantes.

Quadro 2 - Principais Limitações da Qualificação

\begin{tabular}{|c|}
\hline Falta de tempo para desenvolver as atividades (5) \\
\hline Tempo muito curso para a entrega das atividades (4) \\
\hline Número reduzido de aulas (4) \\
\hline
\end{tabular}

Fonte: Os autores, 2020

Com relação ao tempo, alguns respondentes justificaram destacando as dificuldades para conciliar as atividades docentes e a realização do curso, em meio à pandemia de COVID-19. Com o ensino remoto ficou claro que o volume de trabalho dos docentes aumentou, tendo-se em vista a necessidade de preparação prévia de diferentes materiais didáticos-digitais, além do tempo necessário para corrigir as atividades e responder as mensagens dos alunos. Esta afirmação é corroborada por um levantamento realizado pela CNTE (Confederação Nacional dos Trabalhadores em Educação) (OLIVEIRA, 2020).

A última parte do instrumento de pesquisa era um espaço aberto para sugestões para as próximas edições da qualificação. As principais sugestões, também categorizadas, são apresentadas no Quadro 3.

Quadro 3 - Principais Sugestões

\begin{tabular}{|c|}
\hline Explorar outras ferramentas da plataforma (4) \\
\hline Realizar uma segunda etapa da qualificação, com conteúdos mais avançados (2) \\
\hline Mais tempo de qualificação (3) \\
\hline Propor a realização de mais atividades práticas (2) \\
\hline
\end{tabular}

Fonte: Os autores, 2020

Alguns participantes também destacaram a importância dos materiais didáticosdigitais utilizados ficarem disponíveis por mais tempo: "Penso que o material poderia ficar permanente para os cursistas pois sempre tenho dúvidas por mais que aprendemos muito com o curso". As sugestões apresentadas serão analisadas pela equipe do projeto, para verificar a possibilidade de aplicação nas atividades das próximas turmas e/ou propostas de futuras qualificações.

\section{Considerações Finais}

Entre os resultados do projeto estão a elaboração e/ou seleção de materiais didáticosdigitais que poderão ser utilizados em outras edições da qualificação e, também, 
disponibilizados gratuitamente na web, para que possam ser aplicados, modificados e replicados em outras capacitações, de diferentes instituições de ensino.

A aplicação de TDICs, em especial a utilização de AVAs (tais como o Google Classroom) não são rotineiras para a maioria dos docentes de diferentes níveis de ensino e instituições brasileiras (Franco, 2020; Godoy, 2020; Instituto Península, 2020). Neste contexto, ressalta-se a importância do desenvolvimento desta e de outras qualificações para os docentes, especialmente os que atuam em instituições públicas.

Com relação aos impactos sociais do projeto, acredita-se que, atuar em prol da formação dos docentes da Educação Básica impactará, positivamente, no aprimoramento destes profissionais, bem como ampliará a importância de se aplicar os recursos de TDICs no fazer pedagógico, especialmente em tempos de isolamento social devido à pandemia da COVID-19.

Os resultados da avaliação realizada com a primeira turma demonstram que o curso está sendo bem avaliado pelos participantes, mesmo tendo-se um nível de evasão bastante alto. Acredita-se que a evasão se dê por conta das atividades práticas e, também, pelo volume elevado de trabalho que alguns docentes das Escolas Públicas Estaduais possuem, especialmente em se tratando do momento de isolamento social e do atendimento remoto de um grande número de turmas e alunos.

\section{Referências}

Bardin, L. (2010) “Análise de conteúdo”. 4. ed. Lisboa: Edições 70.

Coradini, L. (2020) "Ensino remoto durante crise pandêmica agrava as desigualdades".

Sul 21. Disponível em: <https://www.sul21.com.br/opiniaopublica/2020/05/ensinoremoto-durante-crise-pandemica-agrava-as-desigualdades-por-lucas-coradini/> . Acesso em maio, 2020.

Costa, D. (2020) "Estabelecido plano de ações para as escolas estaduais durante o período de suspensão das aulas". Disponível em https://educacao.rs.gov.br/seducestabelece-plano-de-acoes-para-as-escolas-estaduais-durante-o-periodo-desuspensao-das-aulas. Acesso em: abr. 2020.

Franco, G. (2020) "Coronavírus: professores falam dos desafios e vantagens de trabalhar em casa". Disponível em: https://educador.brasilescola.uol.com.br/noticias/coronavirus-professores-falamdos-desafios-e-vantagens-de-trabalhar-em-casa/33270.html. Acesso em maio, 2020.

Godoy, J. (2020) "Professores e alunos falam sobre desafios e dificuldades de aulas online durante pandemia em MS". Portal G1 MS. 21 de maio de 2020. Disponível em: https://g1.globo.com/ms/mato-grosso-do-sul/noticia/2020/05/21/professores-ealunos-falam-sobre-desafios-e-dificuldades-de-aulas-online-durante-pandemia-emms.ghtml. Acesso em maio, 2020.

Google. (2020) "Google Classroom". Disponível em: https://play.google.com/store/apps/details?id=com.google.android.apps.classroom\& hl=pt_BR. Acesso em junho, 2020.

Instituto Península. (2020) "Sentimento e percepção dos professores brasileiros nos diferentes estágios do Coronavírus no Brasil". Disponível em: https://www.institutopeninsula.org.br/pesquisa-sentimento-e-percepcao-dos- 
professores-nos-diferentes-estagios-do-coronavirus-no-brasil/. Acesso em maio de 2020.

Mehlecke, Q.; Descovi, L.; Dörr, C. R. B.; Pereira, S. C. (2019) "Sala de Aula Invertida mediada pelas Tecnologias Digitais: realidade ou necessidade?". Congresso Internacional ABED de Educação a Distância. Disponível em: http://www.abed.org.br/congresso2019/anais/trabalhos/30269.pdf. Acesso em julho, 2020.

Oliveira, E. (2020) Quase 90\% dos professores não tinham experiência com aulas remotas antes da pandemia e $42 \%$ seguem sem treinamento, aponta pesquisa. Portal G1, 08 de julho de 2020. Disponível em: https://g1.globo.com/educacao/noticia/2020/07/08/quase-90percent-dosprofessores-nao-tinham-experiencia-com-aulas-remotas-antes-da-pandemia42percent-seguem-sem-treinamento-aponta-pesquisa.ghtml. Acesso em julho, 2020.

Pimentel, M.; Carvalho, F. S. P. (2020) "Princípios da Educação Online: para sua aula não ficar massiva nem maçante!”. SBC Horizontes, maio 2020. ISSN 2175-9235. Disponível em: <http://horizontes.sbc.org.br/index.php/2020/05/23/principioseducacao-online>. Acesso em: mai, 2020.

Seduc-RS. Secretaria de Educação do Estado do Rio Grande do Sul. (2020) "Começa Implantação das Aulas Remotas na Rede Estadual de Ensino". 02 de junho de 2020. Disponível em: http://portal.educacao.rs.gov.br//Main/Noticia/Visualizar/portalseduc/Comecaimplantacao-das-Aulas-Remotas-na-Rede-Estadual-de-Ensino. Acesso em jun. 2020.

Silva Júnior, S. D.; Costa, F. J. (2014) "Mensuração e Escalas de Verificação: uma Análise Comparativa das Escalas de Likert e Phrase Completion". Revista Brasileira de Pesquisas de Marketing, Opinião e Mídia, v. 15, p. 1-16.

Sponchiato, D. (2020) "Coronavírus: como a pandemia nasceu de uma zoonose". Disponível em: https://saude.abril.com.br/medicina/coronavirus-pandemiazoonose/. Acesso em abril, 2020.

Tenente, L. (2020) "Sem Internet, merenda e lugar para estudar: veja obstáculos do ensino a distância na rede pública durante a pandemia de Covid-19”. Portal G1, 05 de maio de 2020. Disponível em: $<$ https://g1.globo.com/educacao/noticia/2020/05/05/sem-internet-merenda-e-lugarpara-estudar-veja-obstaculos-do-ensino-a-distancia-na-rede-publica-durante-apandemia-de-covid-19.ghtml>. Acesso em maio, 2020.

Toledo, J. V.; Rocha, F. G.; Nunes, A. K. (2018) "Google Classroom: qualificação docente para o uso de novas tecnologias". Cadernos da FUCAMP, v. 17, n. 29. Disponível em: https://www.fucamp.edu.br/editora/index.php/cadernos/article/view/1156/860. Acesso em julho, 2020. 